\title{
Divertissement sériel de Susana Baron-Supervielle: episodios de una obra ambulante
}

\author{
Divertissement sériel by Susana Barón Supervielle: \\ chapters of a travelling work
}

\author{
por \\ Romina Dezillio \\ Instituto Nacional de Musicología "Carlos Vega", Argentina \\ romy_dezillio@yahoo.com.ar
}

\begin{abstract}
Divertissement sériel, para nueve instrumentos, de Susana Baron-Supervielle (1910-2004), fue compuesta en 1952 durante los cursos de composición dictados por Hans-Joachim Koellreutter en la Escola Livre de Música da Pró-Arte de São Paulo, y estrenada por él en su primer viaje a Tokio en 1953. Al año siguiente se estrenó en París. Los rumbos que adoptó la circulación de esta obra remedan los caminos que transitó Susana Baron-Supervielle tras asumir el desafío histórico de practicar la música de su tiempo. Nacida en el seno de una familia vinculada a la intelectualidad porteña, y con lazos de parentesco que la ligaron a Francia, las primeras indagaciones en torno a la renovación de los medios y las técnicas para la composición musical las realizó en París hacia comienzos de los años treinta. A su regreso se radicó en São Paulo y, más tarde, integró la Agrupación Nueva Música liderada por Juan Carlos Paz en Buenos Aires. Este trabajo propone dilucidar las relaciones de Baron-Supervielle con el medio musical paulista; caracterizar su búsqueda compositiva mediante el análisis de la grabación de la obra citada y describir las redes interpersonales que surgen de la circulación de la obra.

Palabras clave: Susana Baron-Supervielle, Hans-Joachim Koellreutter, Escola Livre de Música da Pró-Arte de São Paulo, Agrupación Nueva Música, dodecafonismo.
\end{abstract}

Divertissement sériel, for nine instruments, by Susana Baron-Supervielle (1910-2004), was composed in 1952 during the composition courses given by Hans-Joachim Koellreutter at the Escola Livre de Música da Pró-Arte de São Paulo, and premiered under his conduction during his first trip to Tokyo in 1953. The following year, it was performed in Paris. The path followed by the circulation of the work copies the ways adopted by Susana BaronSupervielle after assuming the historical challenge of practicing the music of her time. Born in the bosom of a family close to the intellectuality from Buenos Aires, and with relatives in France, she made her first inquiries around the renovation of the musical language at the beginning of the 30's. After that, she settled in São Paulo and, later, she was part of Agrupación Nueva Música leaded by Juan Carlos Paz in Buenos Aires. The aim of this paper is to elucidate the relations that Baron-Supervielle established with the musical environment of São Paulo; characterize her compositional practice through the analysis of the recording of the mentioned work; and describe the interpersonal nets that emerge from the circulation of the work.

Keywords: Susana Baron-Supervielle, Hans-Joachim Koellreutter, Escola Livre de Música da Pró-Arte de São Paulo, Agrupación Nueva Música, dodecaphony. 


\section{NARRAR LA DISPERSIÓN ${ }^{1}$}

La dispersión espacial y temporal de múltiples fragmentos ha sido el primero y el principal desafío para llevar adelante este estudio. Divertissement sériel para nueve instrumentos comenzó como una línea en el catálogo de obras de Susana Baron-Supervielle, contenido en la entrada léxica del Diccionario de la música española e hispanoamericana (Mansilla 1999: 245). Más tarde, su significación creció a la luz del archivo personal de la compositora que ingresó como donación al Archivo de Música Académica del Instituto Nacional de Musicología “Carlos Vega”, en diciembre de 2016 (Dezillio 2017a)². Documentos de diversa condición y con desigual circulación -tanto privada como pública- (cartas, fotos, recortes periodísticos, informes manuscritos) develaron en aquella mención, huérfana de historia, un proceso rico en significaciones y novedoso en singularidades; y en la proliferación de los datos agregaron complejidad y mayor alcance al objeto.

Sin embargo, ninguna fuente musical que permitiera el análisis de la obra se encontraba disponible, y la contextualización del momento de creación no daba con testigos que la pudieran informar, debido a que se trata del período en el que la compositora residió en la ciudad de São Paulo, Brasil. La partitura permanece todavía ausente, pero esta falta fue parcialmente compensada con el acceso al registro fonográfico de la audición radial que la difundió en París. Para el acercamiento al contexto de creación, resultaron imprescindibles los relatos de Luiz Carlos Vinholes (Pelotas 1933), compositor y escritor brasileño, compañero de estudios de Susana, quien se convirtió en un cronista asiduo de múltiples recuerdos acerca del período en el que la obra fue compuesta y estrenada, muchos de ellos atesorados por su afición a la escritura de memorias. Las particularidades de este caso, entonces, han trazado una metodología que combina el estudio de fuentes documentales, el análisis del registro fonográfico y las entrevistas. Asimismo, este trabajo forma parte de las investigaciones acerca del pensamiento musical y el estilo composicional desarrollado por las primeras compositoras profesionales argentinas, que es tema de mi proyecto doctoral en curso.

\section{UNA CRONOLOGÍA PARA FRAGMENTOS DE ESPACIO Y TIEMPO}

Susana Baron-Supervielle nació en Buenos Aires el 10 de junio de 1910. Hija de Esteban Baron y Ana Supervielle, Susana recordaba sus orígenes con un relato de viaje:

Mi abuelo Luis era un ex seminarista cuando decidió venir al Río de la Plata, pero su barco naufragó frente a las costas de Punta del Este [Uruguay]. Nadando se salvó, solo con sus documentos que sostenía en la boca. Se casó con una uruguaya y fundó un banco y nuestra familia. Qué excentricidad (Pinto 1999: 7).

La nacionalidad francesa a la que su abuelo se aferró con los dientes tras cruzar el Atlántico fue la que marcó la idiosincrasia cultural y la sociabilidad de la familia Supervielle, que se amplió entre Argentina y Uruguay. Para Susana significó participar de los hábitos y

1 Una primera presentación de este trabajo tuvo lugar en el III Congreso de Musicología de la Asociación Regional para América Latina y el Caribe, ARLAC/IMS, realizado en la Universidad Católica de Santos, Brasil, del 1 al 5 de agosto de 2017.

2 La donación provino de Inés Baron-Supervielle, sobrina de Susana, a partir de la voluntad de la propia compositora de ceder sus materiales a esta institución, expresada en una carta a Silvina Luz Mansilla, enviada desde San Pablo con fecha 2 de abril de 1990. 
consumos de la elite porteña vinculada a la modernidad musical y literaria. Así, pudo afirmar su vocación de componer desde muy niña; asistir obstinadamente a escuchar conciertos acompañada por su institutriz; y, finalmente, viajar a París a estudiar música con Nadia Boulanger a comienzos de los años treinta. También realizó estudios de contrapunto con otra mujer, Andrée "Vaura" Vaurabourg (1894-1980), destacada pianista vinculada al grupo de Los Seis, intérprete dilecta de la música para piano de Arthur Honegger, con quien había contraído matrimonio en 1917, y reconocida como una de las mejores profesoras de armonía, contrapunto y fuga en la ciudad (Spratt 1980: 679). A su regreso a Buenos Aires, Baron-Supervielle entabló vínculos y acompañó la trayectoria del grupo de intelectuales en torno a la Revista $\mathrm{Sur}^{3}$.

Este mismo cauce condujo la edición de una de sus primeras composiciones por la casa editora Maurice Senart, destacada por la publicación de obras de compositores modernistas como Alfredo Casella, Francesco Malipiero, Darius Milhaud y Arthur Honegger (Nichols 1980: 126).

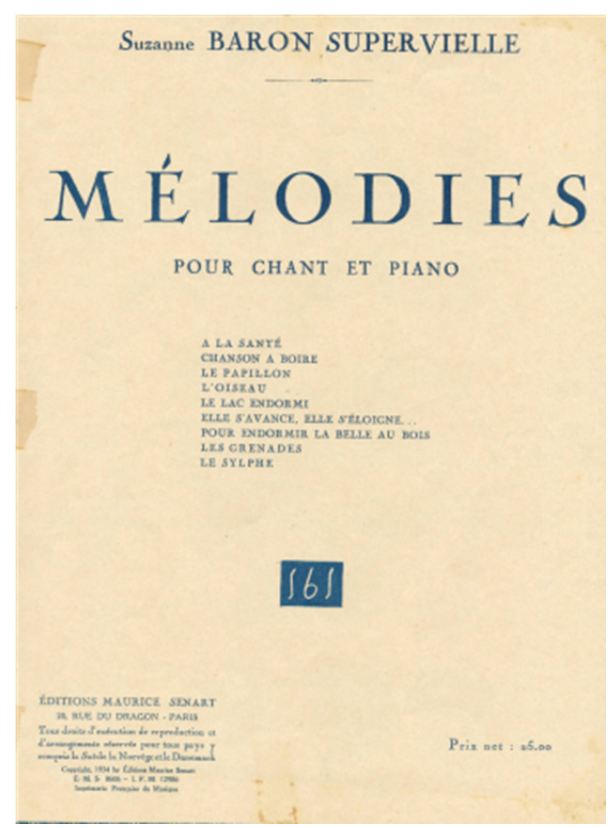

Figura 1: Baron-Superville, Susana. Portada de Mélodies

Esta primera obra editada es Mélodies pour chant et piano, y así como el título, el nombre de su autora figura en versión francesa: Suzanne Baron-Supervielle ${ }^{4}$ (ver Figura 1).

${ }^{3}$ Para un estudio acerca de la participación de este colectivo, liderado por Victoria Ocampo, en la modernidad musical, ver Corrado 2010: 135-162.

${ }^{4}$ El detalle de este ciclo es el siguiente: 1). "A la Sante" [Estrofa V], G. Apollinaire; 2) "Chanson à boire" [aunque la compositora lo atribuye a Raoul Ponchon, el texto corresponde a una estrofa del poema "Conseil falot. À Raoul Ponchon" de Paul Verlaine]; 3) "Le papillon", P-J. Renard; 4). "L'Oiseau", Marie Laurencin; 5) "Le lac endormi”; 6) "Elle s'avance, elle s'éloigne...”; 7) "Pour endormir la Belle 
El ciclo está precedido por otros dos: Dos melodías criollas de 1928, acerca de poemas nativistas de los uruguayos Fernán Silva Valdés (1887-1975) y Benjamín Fernández y Medina (1873-1970) y Tres pequeños coros, para voces mixtas y piano, de 1932, que musicalizan la traducción al francés de un texto tradicional de Buta, norte de la República Democrática del Congo, y dos textos de la misma compositora. Ambos ciclos fueron estrenados por Jane Bathori y la autora al piano en la sala Amigos del Arte de la ciudad de Buenos Aires en 1934. Es importante destacar, como señala y analiza Omar Corrado, la centralidad de la música francesa en los repertorios que circularon en esta sala, "no solo los interpretados por músicos de ese origen sino, y sobre todo, por pianistas y cantantes porteños educados, por los hábitos de su clase, en la cultura y lengua francesas" (Corrado 2010: 92). Del mismo modo conviene recordar que la cantante y pianista francesa Jane Bathori (1877-1970) residió en Buenos Aires entre 1926 y 1946 y tuvo una participación destacada en el movimiento musical local (Valenti Ferro 1992: 66-69). Testigo de los vínculos de sociabilidad que acompañaron el desenvolvimiento artístico de Susana Baron- Supervielle puede considerarse una carta que Bathori escribió al compositor y musicógrafo francés Charles Koechlin (1867-1950) después del estreno de estas obras en Amigos del Arte, anunciando un viaje de Susana a París. Con el propósito de presentarla, destaca:

Tengo el placer de presentarle a Suzanne Baron-Supervielle que acaba de casarse con un francés de acá, Georges Tresca. Trabajó en París con Nadia Boulanger, luego aquí estudió armonía con Jacqueline Ibels ${ }^{5}$. Nosotros hemos hecho el otro día una audición de algunas de sus melodías y de Tres pequeños coros de ella, y han tenido mucho éxito. / Ella va a pasar un mes en París y quisiera mostrarle lo que hace ${ }^{6}$.

En la mediación de la misma Bathori con esta solicitud a Koechlin ${ }^{7}$ resulta clara la intención de poner en evidencia el ejercicio y consumo de la cultura francesa de BaronSupervielle tanto en su formación como en sus hábitos.

La trama entre música y palabras articula una red de relaciones interpersonales que acompañará toda la carrera compositiva de Baron-Supervielle y que es posible restituir en buena parte en cada uno de los períodos que jalonan su obra. En este sentido se observan, desde una mirada macro, cuatro etapas: luego del ejercicio breve y fugaz con el nativismo

au bois", estos tres últimos de Jules Supervielle; 8) "Les Grenades" y 9) "La sylphe", de Paul Valery. Algunas de estas canciones fueron estrenadas por la autora al piano acompañando a Dora Berdichevsky en 1944 en el Instituto Francés de Estudios Superiores, y otras participaron de una audición de música argentina organizada por Jane Bathori para la Sociedad América Latina de París (Dezillio 2017b: 5).

5 Pianista francesa, activa en los círculos de música contemporánea porteña a partir de los años treinta. Durante los primeros años de esta década se observa el desempeño asiduo de Ibels en los conciertos que tuvieron lugar en Amigos del Arte (Corrado 2010: 92, 96, 98). Del mismo modo es recurrente su participación en los organizados por el Grupo Renovación en la misma época (Scarabino 1999: 112 y ss.). También es frecuente su actuación como acompañante de Jane Bathori.

6 Carta manuscrita originalmente en francés: Cher ami, / J'ai le paisir de vous présenter Suzanne Baron Supervielle qui vient de se marier avec un Français d'ici Georges Tresca. Elle a travaillé á Paris avec Nadia Boulanger puis ici a fait de l'harmonie avec Jacqueline Ibels. Nous avons fait l'autre jour une audition de quelques mélodies a de 3 petits chours d'elle qui ont en beaucoup de succès. / Elle va passer un mois à Paris a voudrait vous montrer ce qui elle fait. Agradezco esta traducción a Juan Ortiz de Zárate. Documento perteneciente al Fondo personal Susana Baron-Supevielle, Archivo de Música Académica del Instituto Nacional de Musicología "Carlos Vega" [En adelante FPSBS-AMA-INMCV].

7 Sabemos que algunos textos de Charles Koechlin circularon en versión castellana, hacia fines de los años veinte, en revistas culturales de la ciudad de Buenos Aires. Del mismo modo, algunas de sus obras fueron ofrecidas en ediciones locales (Corrado 2010: 181). 
que inició su repertorio en 1928, Baron-Supervielle se dedicó a musicalizar poesía en francés (Apollinaire, Verlaine, Renard, Marie Laurencin, Jules Supervielle, Valéry). En 1940 compuso un primer ciclo sobre Cuatro canciones de Federico García Lorca, y un segundo ciclo le pone música a las nueve "Andaluzas" (Nueve canciones) en 1952, ambos editados por Ricordi $^{8}$. Esta ecuación -entre poesía y música- fue la predilecta de Baron Supervielle a la hora de componer, con la excepción de un período de diez años (1947-1957) que constituyó un segundo momento para su repertorio, en el que dedicó sus esfuerzos a la música instrumental: Cuarteto para cuerdas, obra inédita de 1947 a la que referiré más adelante; Sonatina en tres movimientos y Estudio, ambas de 1949, escritas para piano y editadas por la casa Ricordi Americana; Composición 57 para pequeño conjunto instrumental y percusión, de 1957, y Divertissement sériel (1952) que aquí estudiamos. Por lo menos una docena de poesías de su tío Jules Supervielle (1884-1960) constituyeron un retorno en todas las décadas; tres poemas de su sobrina Silvia Baron-Supervielle (1934) -argentina residente en Francia desde 1961- también reafirmaron las afinidades de la genealogía familiar. Seguidora de Pierre Schaeffer y de los trabajos de sus colaboradores en el Grupo de Investigación de Música Concreta en París (Groupe de Recherche de Musique Concrète) desde fines de los años sesenta, Baron-Supervielle se dedicó prioritariamente a la música electroacústica con la composición de unas diez obras para cinta magnética ${ }^{9}$. No abandonó, sin embargo, la puesta en música de poemas, sino que se acercó al movimiento de poesía concreta en Brasil: en 1969 musicalizó el poema concreto Vida, de Augusto de Campos, para canto solo, que más tarde será "injertado", en términos de la compositora, en la obra Le chaos et la création para cinta magnética (1974) basada, a su vez, en un poema de Jules Supervielle ${ }^{10}$.

A partir de 1984 se sitúa el encuentro con la poesía de Alejandra Pizarnik: hasta 1987 se suceden los Diez poemas de Alejandra Pizarnik; de 1993 es el ciclo Nueve instantáneas, que se amplía a Doce instantáneas con la musicalización de tres nuevos poemas en 1996; y ambos ciclos reunidos y ampliados constituyen los Veintinueve poemas cantados de 1999 prologados por "Llama de amor viva" de San Juan de la Cruz, y "Un poète" a modo de epílogo, del persistente Jules Supervielle11 (Dezillio 2017b: 7).

En 1936, Susana Baron-Supervielle se estableció en São Paulo (con su marido, Georges Tresca -un industrial textil-), donde residió durante más de cuarenta años, aunque las estancias en Buenos Aires y en París fueron periódicas. Consecuente con sus inicios, en aquella ciudad también buscó participar de las experiencias que proponían los nuevos lenguajes sonoros: primero el dodecafonismo y más tarde la música electroacústica.

En 1952, tras quince años de residencia, asistió a los cursos promovidos por la Escola Livre de Música de São Paulo a la sazón inaugurada por la Asociación Pró-Arte, y que contaba con la dirección artística de H-J. Koellreutter ${ }^{12}$. Esta es la época en la que, luego de internacionalizar las prácticas llevadas adelante en Brasil con los viajes a Darmstadt y a

8 Un estudio sobre la puesta en música de la poesía de Lorca en Dezillio 2019.

9 La profundización en este repertorio, sus condiciones de producción y circulación, es abordada en un estudio en progreso que es parte de mi desempeño en el equipo UBACyT Música 'culta'y literatura en Argentina. Algunos repertorios vocales del siglo XX, dirigido por la Dra. Silvina Luz Mansilla.

10 Finalmente, Baron-Supervielle tituló esta obra Vida.

11 Este ciclo se estrenó el 21 de agosto de 1999 en La Carbonera de San Telmo con puesta en escena de Vivi Tellas y las actuaciones de la mezzosoprano Nélida Saporiti y la bailarina Silvia Gómez Giusto. También cuenta con una grabación comercial en CD: 29 poemas cantados. Composiciones de Susana Baron- Supervielle con poemas de San Juan de la Cruz, Alejandra Pizarnik y Jules Supervielle. Canto: Nélida Saporiti.

12 H-J. Koellreutter fue director artístico entre 1952 y 1956. Los sucesivos directores fueron: Roberto Schnorrenberg (1957-1960), Arthur Hartmann (1961-1964), Gilberto Tinetti (1965), Maria Helena da Silveira y Yolanda Borgoff (1968) (Vinholes 2011c). 
la Bienal de Venecia (Fugellie 2013: 4 y ss), Koellreutter se había establecido finalmente en la capital paulista buscando una mejor recepción para el dodecafonismo, tras el asedio de la crítica sufrido en Río de Janeiro (Pinheiro de Avila 2016: 45). Esos también son los años de su primer viaje a Japón, que involucraron a Baron-Supervielle y su Divertissement sériel, porque es en Tokio donde se produce el estreno de esta obra, el 13 de noviembre de 1953. Al año siguiente, la Difusora de Radio y Televisión Francesa ${ }^{13}$ realizó una transmisión radial de la obra en París. Este registro fonográfico constituye hoy, como ya se adelantó, la única fuente de la obra completa ${ }^{14}$ (ver Figura 2).

\begin{tabular}{ll} 
Oeuvre de Suzanne baron-SUPERVIELLE \\
\hline Numéro : & PHD86033723 \\
Chaîne : & Programme National \\
Date de diffusion : & 12.06 .1954 \\
Statut de diffusion : & Première diffusion \\
Heure de diffusion : & $16: 50: 00$ \\
Heure de fin de diffusion : & $17: 18: 15$ \\
Thématique : & Musique \\
Genre : & Interprétation \\
Nature de production : & 01 \\
Canal : & OM \\
Jour : & samedi \\
Type de description : & Emission simple \\
Générique : & INT,Constant Marius \\
Oeuvres : & Divertissement pour neuf instruments / Auteur : Baron-SUPER VIELLE \\
Date d'enregistrement : & 10.06 .1954 \\
Société de programmes : & RTF \\
Producteurs : & Producteur, Paris : Radiodiffusion Télévision Française, 1954
\end{tabular}

Figura 2: Ficha catalográfica de la obra depositada en la Biblioteca Nacional de Francia.

La exploración del itinerario que sigue esta composición permite vislumbrar correspondencias con una última autoridad: Juan Carlos Paz y la Agrupación Nueva Música, por él liderada.

Una aproximación a la creación y la circulación de esta composición pone en evidencia las confluencias que Susana Baron-Supervielle señala como constitutivas de su "identidad musical" (Baron-Supervielle 1999), una identidad que metaboliza el vaivén de sus estancias entre Buenos Aires, París y São Paulo, y que favorece esta obra con una escala en Tokio para su estreno a cargo de H-J. Koellreutter, quien fuera su maestro guía en el proceso de composición. Estas consideraciones permiten, además, aproximarse al pensamiento musical

13 En el idioma original: Radiodiffusion-Télévision Française. En adelante RTF.

14 El documento sonoro se encuentra en la sección Ina Teque, depósito legal de la RTF, con sede en la Biblioteca Nacional de Francia. El acceso al registro sonoro fue mediante una plataforma online de ingreso restringido a profesionales por tiempo limitado y con un sistema de usuario y contraseña. La ubicación del documento es la siguiente: https:/ /www.inamediapro.com/eng/notice/ PHD86033723?preview=1 El período de acceso al archivo expiró el 31 de agosto de 2017, para renovar el acceso se debe contactar a inamediapro@ina.fr 
que Susana Baron-Supervielle irá desenvolviendo a lo largo de toda su obra. Una obra vertebrada por la puesta en música de más de cien poemas, con un lenguaje que comienza con exploraciones modales influenciadas por el impresionismo debussyano y que va asumiendo la llamada emancipación de la disonancia hacia un serialismo libre. La misma parábola recorren sus obras instrumentales: de las primeras composiciones para piano solo -en estilo impresionista y sensible a la influencia del neoclasicismo raveliano- a los ensambles de cámara que ensayan el dodecafonismo. Para afrontar la experimentación con sonidos concretos y la composición electroacústica, Susana montó un "elemental" laboratorio en São Paulo ${ }^{15}$. Respecto de esta producción, el curriculum vitae de la compositora se amplía: "Susana ha instalado en su residencia de San Pablo el primer Estudio-Laboratorio de música electroacústica de Brasil”16. Sin embargo, es importante aclarar que el interés por la música electroacústica en aquella ciudad puede rastrearse desde 1953, y hay documentación que testimonia la existencia de un "estudio de música electrónica" en la misma Escola Livre de Música Pró-Arte, a cargo de Ernst Mahle y H. J. Koellreutter, inaugurado en 1954 (Vinholes 2013a: 31) ${ }^{17}$. Inclusive un programa de las clases de composición impartidas por Koellreutter en São Paulo, difundido en el verano de 1953-54, incorpora "composición para instrumentos electrónicos" entre las prácticas (Vinholes 2013a: 34) ${ }^{18}$. De modo que es probable que el ejercicio de estas técnicas, aunque Baron-Supervielle siempre las adjudicó a la influencia de la pionera escuela francesa, haya sido también incentivado por la efervescencia de estos antecedentes en el ambiente paulista. Luego será la Agrupación Nueva Música quien estrene todas sus obras de este repertorio durante los años setenta en Buenos Aires ${ }^{19}$.

\section{Episodio I: São Paulo, 1952}

La Escola Livre de Música de São Paulo fue creada por la sociedad Pró-Arte, y sus actividades se inauguraron en marzo de $1952^{20}$. Con Koellreutter como su primer director artístico,

15 "Un laboratorio elemental, solamente tres grabadores, porque los filtros son muy caros". "Muera el solfeo”, Primera Plana (26 de julio, 1966), p. 85. Documento perteneciente al FPSBS-AMA-INMCV.

16 Documento perteneciente al FPSBS-AMA-INMCV.

17 Luiz Carlos Vinholes reconstruye y documenta los inicios de esta actividad en Brasil en su artículo Música eletrônica no Brasil nos anos 1950 (2013a). Entre las actividades se destaca un número importante de conferencias en torno al tema, entre ellas una a cargo de Pierre Boulez: Problemas de la música contemporánea y de la música concreta en particular (1954). Además, cuatro conferencias relativas a Problemas técnicos y estéticos de la música concreta a cargo de Ernst Mahle y Koellreutter "como parte del programa de inauguración del sector de música electrónica de La Escola Livre de Música”, también en 1954. Un evento relevante fue el estreno de la obra Contrapuntos de Karlheinz Stockhausen, entre otros acontecimientos que articulan los comienzos de esta práctica en Brasil (Vinholes 2013a: 31-33).

18 Escuchar a Samuel Kerr, "Escola Livre de Música”, en Ideias musicais (programa de radio online). Se trata de un ciclo de trece emisiones en las que el autor revisa y reconstruye la historia social, cultural y sonora en torno a la Escola Livre de Música, en el período liderado por Koellreutter. Para información relativa al tema de la música electroacústica, escuchar programa del 22 de mayo de 2013. Disponible en: http://culturafm.cmais.com.br/escola-livre-de-musica. [acceso: 28 de noviembre de 2019]

19 En esta materia, Susana Baron-Supervielle integró el colectivo fundador de Arte 11 (Atelier de Realizaciones Técnico Electroacústicas de Buenos Aires) junto con Luis María Serra y Lionel Filippi, en 1971, y fue miembro la Federación Argentina de Música Electroacústica.

20 El desenvolvimiento que da lugar a la constitución de esta institución tiene una genealogía de ascendencia europea. El comienzo se sitúa en 1924, en Río de Janeiro, con la llegada de un joven alemán llamado Theodoro Heuberger (Munich 13-01-1898): pintor y animador cultural que fue invitado de un pintor diplomático brasileño, Navarro da Costa. Pronto se convirtió en un representante de Alemania en Brasil e instaló en Río de Janeiro la "Galeria Heuberger”. En 1931, con la colaboración 
la nueva institución proponía el principio de "libertad creadora" como la base de la nueva orientación pedagógica. Según transcribe la reseña del diario O Estado de São Paulo, en la inauguración Koellreutter promovía la sustitución del

programa basado en la imitación del pasado - ese conjunto de fórmulas que, bajo el rótulo de una falsa tradición, ahogan lo que haya de positivo en el sentido de Creación en el joven artistapor un programa capaz de estimular la fuerza creadora y desarrollar la personalidad del alumno (citado en Vinholes 2013b) ${ }^{21}$.

Con este propósito, materias como "solfeo, armonía y contrapunto, [...] tan importantes para el músico profesional, serán dadas en clases de tres alumnos solamente, garantizando así la eficiencia de los estudios". Y sigue:

El alumno que asiste a la Escola Livre de Música estudiará y conocerá la literatura integral, de la Edad Media a nuestro tiempo, y no se restringirá solo a dos siglos de la tan rica historia de la música. [...] Así, la Escola Livre de Música de São Paulo, huyendo de los patrones tradicionales, no proporcionará diplomas oficiales, ni procurará conectarse a la enseñanza oficial u oficializada: se mantendrá como un conjunto de seminarios de arte, dirigidos por maestros de reconocido mérito (citado en Vinholes 2013b) ${ }^{22}$.

Desde los inicios de la Escuela, Baron-Supervielle participó de las clases de composición de Koellreutter y junto con el ensayo de la técnica dodecafónica comenzó la creación de Divertissement sériel en la que también convergen los aprendizajes respecto de instrumentación de las clases con Conrad Bernhard (Vinholes 2011b) ${ }^{23}$.

de la pianista María Amelia de Rezende Martins, creó la Sociedad Pró-Arte con la finalidad de divulgar las Artes, las Letras y las Ciencias. Tras su arribo en 1937, H-J. Koellreutter es presentado a Theodoro Heuberger y comienza a realizar recitales de flauta en las temporadas de Pró-Arte, estableciéndose entre ellos una relación de trabajo y amistad. En 1939, llegó a Brasil la cantante austríaca, Hilde Sinnek, famosa por sus actuaciones en Bayreuth, y se estableció como profesora de canto en Río de Janeiro hasta que, en 1941, pasó a enseñar en el Conservatorio Brasileño de Música, definiendo la carrera de muchos cantantes brasileños. En las vacaciones de enero de 1949, Hilde Sinnek invitó a sus alumnos para unos días de convivencia musical en su casa en Teresópolis y pidió al profesor Koellreutter que fuera a hablar con ellos acerca de música. Luego de esta experiencia, el mismo Koellreutter, con el apoyo de Theodoro Heuberger, funda, organiza y dirige el Curso Internacional de Vacaciones Pró-Arte, en Teresópolis, iniciando una práctica que se va a hacer tradicional en aquella ciudad y que será difundida entre otras ciudades brasileñas. En 1952, después de realizado el III Curso de Teresópolis, Koellreutter logra finalmente una sede para el desarrollo de su ideario con la Escola Livre de Música (una casa de dos plantas de cuatrocientos años de antigüedad, alquilada por Heuberger) (Vinholes 2011b; Nogueira y Rosa 2012).

21 Todas las traducciones del portugués son propias. Texto original: Substituiu-se o programa baseado na imitação do passado -esse conjunto de receitas que, sob o rótulo de uma falsa tradição, sufocam o que houver de positivo no sentido de criação no jovem artista- por um programa capaz de estimular a força criadora e desenvolver a personalidade do aluno.

22 Texto original: Solfejo, harmonia e contraponto [...] matérias tão importantes para o músico profissional, serão dadas em classes de três alunos somente, garantindo-se assim a eficiência dos estudos. $O$ aluno que frequenta a Escola Livre de Música estudará e conhecerá a literatura integral, da Idade Média ao nosso tempo, e não se restringirá apenas a dois séculos da tão rica história da música. [...] Assim, a Escola Livre de Música "São Paulo", fugindo aos padrões tradicionais, não fornecerá diplomas oficiais, nem procurará ligar-se ao ensino oficial ou oficializado: manter-se-á como um conjunto de seminários de arte, dirigidos por mestres de reconhecido mérito.

23 Además de las clases de orquestación, Conrad Bernhard tenía a su cargo las clases de lectura de partituras, lectura a primera vista e improvisación (Vinholes 2011b). 
Como se mencionó más arriba, Baron-Supervielle se había establecido en São Paulo en 1936. Dos años antes, en 1934, se sitúan las primeras composiciones dodecafónicas de Juan Carlos Paz en Buenos Aires. Cuando en 1937, Koellreutter introdujo esta técnica en Brasil, Paz inicia los Conciertos de la Nueva Música en Buenos Aires. Dos años después, en 1939, Koellreutter funda el Grupo Música Viva en Río de Janeiro, que compartía los principios estéticos de los Conciertos de la Nueva Música pero expresaba más explícitamente su posicionamiento ideológico y su acción política. En medio de diversas actividades tendientes a la renovación de la música brasileña, en 1944 se constituyó un grupo homónimo de compositores promotores del atonalismo y el dodecafonismo, que fue desmembrándose progresivamente entre 1948 y 1950 (Paraskevaídis 1985). En su estudio A composição de Eunice Katunda no contexto político e musical brasileiro, Amilcar Zani, Eliana Monteiro da Silva y Marisa Milan Candido sostienen que "el contexto histórico y político que permitió la visibilidad lograda por Música Viva en 1946 fue la entrada de Eurico Gaspar Dutra en la presidencia, [...] quien estableció un gobierno liberal y abierto a la internacionalización" (2019: 120). Según las autoras, la política nacionalista previa implementada por el gobierno de Getúlio Vargas desalentaba las prácticas tendientes al abstraccionismo y al formalismo. El retorno de G. Vargas electo nuevamente en 1950 y su alianza con referentes culturales del nacionalismo musical como Camargo Guarnieri, protagonista del conocido episodio desatado a partir de su Carta Aberta aos Músicos e Críticos do Brasil, terminaron de sofocar todas las actividades de Música Viva (Zani et al. 2019: 120). De modo que en los años en que Susana comenzó a ejercitar la técnica dodecafónica a partir de sus aprendizajes en la Escola Livre de Música, los pioneros locales habían optado por un retorno al nacionalismo musical24.

\section{La composición musical de Divertissement sériel}

A lo largo de su circulación, la obra que estudiamos se presenta con diferencias en su título: Divertissement sériel; Divertissement pour neuf instruments; Divertimento; Divertimento serial. A pesar de las diferencias, se mantiene firme su voluntad de ser, ante todo, un Divertimento, como el mismo Koellreutter lo refirió cuando preparaba su estreno en Tokio. De la forma musical popularizada durante el siglo XVIII, conserva su estructura en números y su instrumentación reducida.

La obra presenta una disposición en once números y está escrita para nueve instrumentos solistas: un quinteto de vientos (flauta, clarinete, fagot, saxo tenor y trompeta); y cuarteto de cuerdas (dos violines, viola y violonchelo). El orgánico también es descrito como cuarteto de cuerdas, cuarteto de soplos y trompeta, lo que suscita una primera asociación con La pregunta sin respuesta de Charles Ives. El conjunto completo, sin embargo, se presenta una única vez en el último número. Los números previos están escritos para dúos, tríos, cuartetos y un sexteto, que combinan instrumentos de una o de ambas familias; su denominación responde justamente a la instrumentación de cada número, y no a su movimiento como es usual. En este sentido, se observa una tendencia a la homogeneidad, sin grandes contrastes de tempi, movimiento y dinámica entre los distintos números, sino que estos suceden en el plano de la instrumentación y la articulación de los sonidos de la serie ${ }^{25}$.

Los once números son los siguientes:

24 Me refiero a los fundadores de Música Viva, con la excepción de Koellreutter: Claudio Santoro, César Guerra Peixe, Edino Krieger y Eunice Katunda.

25 Agradezco a María Emilia Greco y Pablo Jaureguiberry por los comentarios acerca de su experiencia de audición de esta obra. 


\author{
I. “Aquí fanfarria" [0’47”]26 \\ II. "Cuarteto de viento" [3'08"] \\ III. "Dúo de viola y violonchelo" [1'16] \\ IV. "Trío de flauta y dos violines" [2'06"] \\ V. "Conversación importante: saxo y clarinete" [1'35"] \\ VI. "Sexteto" [2'42"] \\ VII. "Dúo de flauta y viola" [2'04"] \\ VIII. "Trío de Flauta, clarinete y fagot" [1'36"] \\ IX. "Cuarteto de cuerdas" [3'23"] \\ X. "Cuarteto de vientos" [3'23"] \\ XI. "Finalmente: cuerdas contra vientos" [3'56"] ${ }^{27}$.
}

Ya que no he podido hallar aún la partitura completa, voy a dejar de lado en esta ocasión los aspectos que aluden a los procesos internos del material dodecafónico y me dedicaré a aquellas características que surgen de la audición. El registro sonoro con el que pude trabajar se realizó el 10 de junio de 1954 para la RTF y la transmisión radial es del 12 del mismo mes ${ }^{28}$. Lo único que conocemos de la partitura hasta el momento es el primer material que organiza la serie con el siguiente diseño rítmico ${ }^{29}$ (ver Figura 3):

\title{
Largo $=d 40$
}

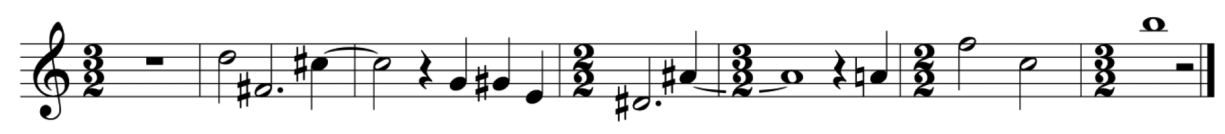

Figura 3: Baron-Supervielle, Susana. Serie original de Divertissement sériel

Este primer material con la serie original es presentado en "Fanfarria" (00:00:36) ${ }^{30}$, por la trompeta como instrumento solista, sobre un acompañamiento realizado por el resto de los instrumentos de viento, que propone un campo disonante con el fraccionamiento armónico de la serie.

26 La información entre corchetes refiere a la duración total de cada número en la interpretación del registro fonográfico citado.

27 Los títulos de los números del Divertimento están transcritos de la grabación según los anuncia un locutor. Deseo agradecer a Thibault de Fontainieu por su ayuda en esta tarea. La versión de los títulos en francés es la siguiente: I. "Voici Fanfare" (00:00:36) [0’47"]/II. "Quatuor à vent" (00:01:20) [3'08"]/III: "Duo alto et violoncelle" (00:04:28) [1'16]/ IV. "Trio flûte et deux violons" (00:05:44) [2'06"]/V. "Conversation importante saxo et trompette" (00:07:49) [1'35"]/VI. "Sextuor" (00:09:25)/ VII. "Duo flûte et alto" (00:12:07) [2'04"]/VIII. "Trio flûte, Clarinette, Basson" (00:14:11) [1'36"]/ IX. "Quatuor à cordes" (00:15:47) [3'56"]/X. "Quatuor à vent" (00:19:44) [3'23"]/XI: "Enfin cordes contre vents" (00:23:06) [3'56"].

28 Información que está presente en la ficha técnica que acompaña el documento sonoro.

29 La transcripción de la serie está tomada del registro de la obra que posee la Sociedad Argentina de Autores y Compositores de Música (SADAIC) con fecha 19 de marzo de 1982 [269532 | ISWC T-037182508-9].

30 La información entre paréntesis remite al momento de inicio de cada número en el registro fonográfico, el que no se encuentra dividido en pistas. 
El primer cuarteto, que es de instrumentos de viento (00:01:20), introduce la propuesta textural de polifonía horizontal, que será predominante a lo largo de toda la obra. La serie es utilizada de manera lineal a partir de un procedimiento por imitación. El comienzo sugiere el género fuga, por la presentación del tema a solo y las entradas imitativas. La presencia de un retardo en el acorde final acusa la remisión al mismo universo sonoro del barroco.

El "Dúo de viola y violonchelo" (00:04:28) introduce el primer contraste en términos de timbre, ritmo y la articulación de los sonidos de la serie. Al comienzo contrapuntístico, confronta una breve sección final en la que sonidos superpuestos en bloque atacan sucesivamente extendiendo su valor de duración, lo que genera una marcada sensación conclusiva.

En el "Trío de flauta y dos violines" (00:05:44), el contraste opera a nivel de registro, por la tesitura misma de los instrumentos y, a nivel formal, por la presencia de tres secciones articuladas por yuxtaposición. Con el "Sexteto" (00:09:25) vuelve a la serie original, mantiene el tratamiento de polifonía horizontal que alterna momentos de distinta densidad cronométrica, hasta que detiene su movimiento en una coda en la que las alturas son superadas por un tratamiento de clusters.

Los números sucesivos presentan el mismo repertorio de procedimientos: un desenvolvimiento formal caracterizado por el flujo continuo de figuras temáticas, casi sin pausas, reforzado por el recurso constante de la polifonía de voces horizontales estructuradas a partir de procedimientos canónicos, fugados no estrictos, y el contrapunto libre. El pulso se mantiene constante dentro de cada número, aunque es recurrente el ritardando y el diminuendo para los finales, que asumen una función conclusiva. Un momento de clímax se da en el octavo número, el trío de maderas (00:14:11), con la suspensión del sentido del pulso, el crescendo dinámico y el incremento de la densidad cronométrica y la heterofonía generada a partir de trinos en los tres instrumentos. También se destaca el retorno al primer material rítmico melódico en la trompeta al final del último número (00:23:06), al modo de una recapitulación.

La obra presenta una clara prioridad de lo sucesivo sobre lo simultáneo, un discurso en el que las relaciones decisivas son las motívicas, un retorno a la naturaleza polifónica de la armonía, en la que la "vida instintiva de las voces individuales", en palabras de Federico Monjeau, no se priva de asumir funciones formales (2004: 19). Sin embargo, la lógica formal del divertimento logra evitar cualquier parentesco con la sonata clásica y con el destino que su plan formal impone a los materiales. Los procedimientos predominantemente contrapuntísticos permiten que la forma surja del carácter del propio material temático. Los números, que desde el título jerarquizan la instrumentación, también señalan el énfasis de los timbres sobre las alturas.

\section{Episodio II: Tokio, 1953}

El 28 de octubre de 1953, Koellreutter le remitió desde Tokio una postal a "Suzana Tresca”31 a la dirección de la Escuela (ver Figura 4).

31 En São Paulo Susana usaba su apellido de casada, Tresca, además de la versión ortográfica nacionalizada de su nombre (Suzana). Es posible aclarar que el nombre de Susana Baron-Supervielle es absolutamente desconocido en el ambiente musical examinado. De hecho, este detalle dificultó bastante la investigación hasta que las indagaciones permitieron comprobar que la compositora era conocida como Suzana Tresca. Debo esta información al mencionado Luiz C. Vinholes, quien compartió clases con Susana Baron-Supervielle en la Escola Livre de Música de São Paulo. Vinholes, además de ser estudiante discípulo de Koellreutter, se desempeñó como su secretario todos los años en que este fue director de la escuela. Com cuidado e com tempo, vou tentar descrever o pouco que sei a respeito da colega Suzana Tresca (como era conhecida aqui). Comunicación personal por correo electrónico (28 de enero de 2017). 
Doña Suzana: el 13 de noviembre estrenaré, con la mejor orquesta de Japón, NHK SymphonyOrchestra de Tokio, en la emisora Nippon Hoku Kyokai, su "Divertimento". En la semana comenzaré los ensayos. Su trabajo fue escogido por la Comisión de Programación de la Emisora. Si es posible, llevaré una grabación, pero no es seguro. Muy cordialmente, Koellreutter ${ }^{32}$.

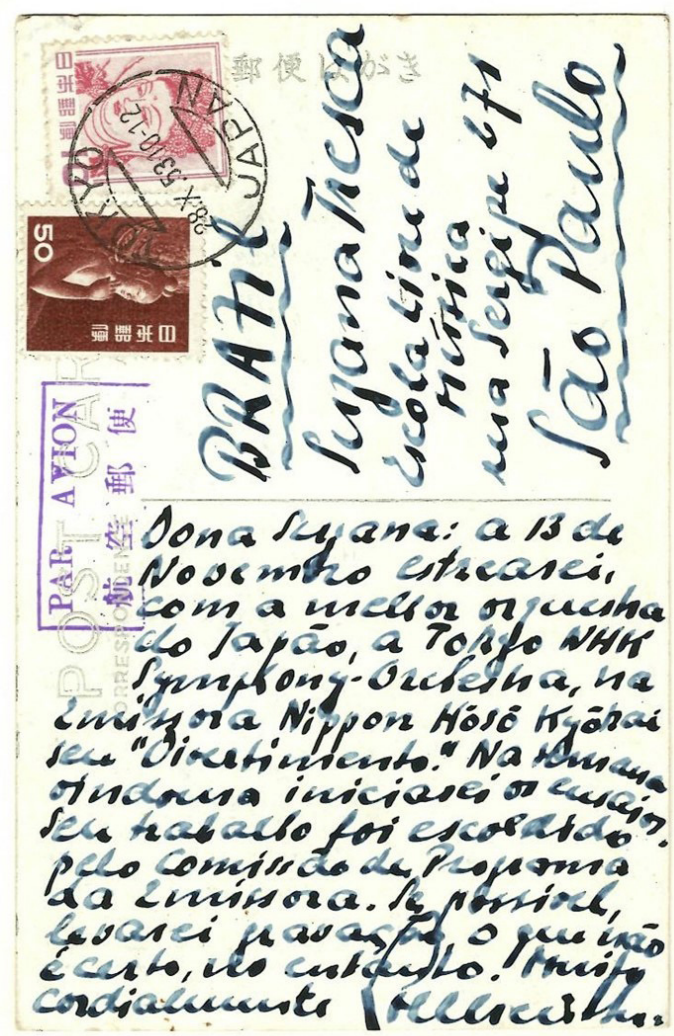

Figura 4: Postal enviada por Koellreutter desde Tokio a Susana Baron-Supervielle

El estreno de Divertimento tuvo lugar en Tokio, y fue una transmisión para la radio Nacional de Japón, NHK [日本放送協会 Hepburn ${ }^{33}$ : Nippon Hōsō Kyōkai], y estuvo a cargo de la Orquesta Sinfónica Japonesa, que desde 1951 recibía el financiamiento de la emisora y había adoptado el mismo nombre.

32 En el original en portugués: Tokyo 28-X-53/ Brazil / Suzana Tresca/ Escola Livre de Música/ Rua Sergipe 271/Sáo Paulo/ Dona Suzana: a 13 de Novembro estrearei, com a melhor orquestra do Japáo, a Tokyo NHK Symphony-Orchestra, na emissora Nippon Hósó Kyokai seu "Divertimento". Na semana [¿ oindoma?] iniciarei os ensaios. Seu trabalho foi escolhido pelo comissao de Programa da Emissora. Se possivel, levarei gravacáo o que náo é certo, no entanto. Muito cordialmente / Koellreutter. [Documento perteneciente al FPSBS-AMA-INMCV].

33 Romanización Hepburn: sistema que se utiliza para transcribir los sonidos de la lengua japonesa al alfabeto latino. 
Estos primeros, y poco conocidos, contactos de Koellreutter con Japón resultan relevantes por el intercambio que posibilitaron con la cultura paulista, además de ser importantes antecedentes de sus más difundidas experiencias en territorio oriental durante los años sesenta y setenta, como enviado del Instituto Goethe. En su carácter de corolario de esta primera visita de Koellreutter a Japón podemos mencionar el hecho de que Kikuko Kanai, compositora japonesa -okinawana-, buscó su guía para aprender la técnica dodecafónica y al año siguiente viajó a Brasil como representante de Japón en las festividades del $I V$ Centerio de São Paulo. Por otra parte, de aquel viaje Koellreutter había traído grabaciones en discos e instrumentos tradicionales japoneses que fueron organizados y difundidos en una muestra por los alumnos de la Escuela ${ }^{34}$.

Los apuntes personales de Luiz Carlos Vinholes han contribuido a confirmar y reconstruir la actividad como compositora que Susana Baron-Supervielle desarrolló en territorio brasileño, que hasta el momento no contaba con registros que la informen. En este sentido, hay que considerar que sus ininterrumpidos vínculos con el ambiente musical e intelectual en torno a Juan Carlos Paz y a la Agrupación Nueva Música mantuvieron su nombre activo en las filas de la música contemporánea en Buenos Aires. Del mismo modo, su ascendencia francesa, ejercida en los vínculos de sociabilidad y actualizada con recurrentes viajes a París, obturó la actividad que Susana llevó adelante en la capital paulista. Sin embargo, de lo que hemos podido estudiar hasta el momento, durante los más de cuarenta años en los que Baron-Supervielle residió en São Paulo, se destaca su actividad durante los años cincuenta por su acercamiento a Koellreutter ${ }^{35}$, y durante las dos décadas siguientes, la composición con medios electroacústicos.

Quizá el estreno del Divertimento en territorio oriental haya dejado el rastro para que, en 1964 en Corea del Sur, se mencionara a Suzana Tresca como una compositora brasileña junto con Eunice Katunda y Geni Marcondes (Vinholes 2011a: 2-3). Resulta elocuente la confusión respecto de la nacionalidad de Baron-Supervielle en un programa de emisión radial que tematizaba los vínculos diplomáticos entre ambas naciones. $\mathrm{Al}$ mismo tiempo, pareciera indudable el carácter mediador de Koellreutter, ya que las tres compositoras mencionadas realizaron estudios con él.

34 Dos años después, y como resultado del segundo viaje de Koellreutter a Japón, la Escuela recibió al profesor y filósofo Masami Kuni creador del “creative dance”, quien junto con Yankaa Rudzka fue uno de los precursores de la danza moderna en Brasil, entre quienes se destaca la profesora Lia Carvalho Robatto, figura central en la enseñanza de la danza en la Universidad Federal de Bahía. (Vinholes 2006: 3).

35 Vinholes denomina al colectivo conformado aquellos años en torno a la Escola Livre de Música "A Grande Família Koellreutter", y entre ellos recuerda los nombres de Celina Sampaio, Maria Rosita Salgado Góes, Damiano Cozzella, Alexandre Shaffman, Conrad Berhnard, Roberto Schnorrenberg, Ersnt Mahle, Yulo Brandão, Dalva Barbosa, Júlio Medaglia, Sandino Hohagen, Henrique Gregori, Carlos Eduardo Prates, Carlos Alberto Pinto Fonseca, Flordinice Maciel Dutra, Paul Urbach, Paulo Affonso de Moura Ferreira, Dirce Luzzi, Munir Bussamra, Norma Graça Floresta, Lídia Hortélio, José Klias, Hortência Ravagnani Montgomery, Maria de Lourdes (Baby) Gregori, José Luiz Paes Nunes, Toshio Takeda, Paulo Herculano, Brasil Eugênio da Rocha Brito, Antonio Galvão Novaes, Maria Aparecida Roméra Pinto Mahle, as irmãs Elisa Helena (Tiche) Memolo Puntoni e Maria Amélia (Meméia) Memolo Cozzella, Henry Jolles, Antonieta Moreira Leite, Ciro Monteiro Brisolla, Eva Milko, Nei Salgado, Klaus Dieter-Wolff, Gerardo Parente, Hilde Sinnek, Cléia Ognibene, Ronaldo Bolonha, Claudio Petraglia, Orlando Leite, Suzana Tresca, Diogo Pacheco, Marli Hatsbach, Dalva Barbosa, Severino Araujo, Tom Jobim, İndio, Araçari de Oliveira, Ula Wolf, Isaac Karabtchevesky, Clara Sverner, as irmãs Marina e Dilza de Freitas Borges, Paulo Herculano, Samuel Kerr, Ula Wolf, Suzana Bandeira de Mello, Terezinha Schnorrenberg, Walter Bianchi, Bino Pedini, Johannes Olsner, Hans e Isolda Bruch, Madalena Nicols, Gabriella Dumaine "entre tantos otros que no cito por falta de memoria" (Vinholes 2006: 7) [Texto inédito, gentileza del autor. El destacado es propio]. 
Paralelamente, la obra de Baron-Supervielle parece haber tenido una circulación escasa en Brasil, y por este motivo no hay recepción periodística, situación que se revierte en alguna medida con la producción de música electroacústica, en torno a esto, ella misma organizó conciertos, participando además con comentarios ${ }^{36}$. A este respecto, Nilcéia Cleide da Silva Baroncelli aporta un factor condicionante: "durante algún tiempo presentó sus obras solo en Europa y Argentina, debido a la falta de salas especiales en Brasil, pero en 1982 participó en un recital de música electroacústica en el MASP [Museo de Arte de São Paulo]" (Baroncelli 1987: 30)37.

Resulta significativa la inclusión de Susana Baron-Supervielle en el libro paradigmático de Nilcéia Cleide da Silva Baroncelli, Mulheres compositoras: elenco e repertório, de 1987. En primer lugar, se destaca que la entrada es con su nombre en versión castellana (ni Suzana como se la conocía en el ambiente musical de São Paulo en los años cincuenta, ni Suzanne como la refiere su círculo familiar y social). Es importante tener en cuenta que este libro de Baroncelli es el primero dedicado a las mujeres compositoras de música académica del Brasil y que, aunque publicado en 1987, reúne información que su autora recopiló desde los años setenta ${ }^{38}$. Eliana Monteiro da Silva define el desenvolvimiento de las compositoras brasileñas en el contexto de la música erudita como una "historia de lucha contra la invisibilidad" y recupera, en sus investigaciones, muchas de las referencias disponibles gracias a los trabajos de Baroncelli. Sin embargo, es consciente de la inevitable pérdida causada por la distancia temporal respecto de la época en que actuaron estas compositoras, y el consecuente olvido (Monteiro da Silvia 2017: 44) ${ }^{39}$. La información que contiene el texto indica:

Compositora argentina contemporánea. Vive en Brasil desde 1936. Desde 1945 en adelante, se unió a la vanguardia de la música clásica, aprendió sobre el trabajo de Pierre Schaeffer y luego se convirtió en una experta en música electroacústica. [...] Obras de arte: Música tradicional: Nueve Canciones, 1952, texto de García Lorca, de Romancero Gitano ${ }^{40}$; Cuatro Canciones, mismo texto, del libro Canciones. Música electroacústica: Vida; Allá; Angustia; Acuario; Espiral (Baroncelli 1987: 29-30) (resaltado en el original).

La selección respecto de su catálogo, así como la exclusiva referencia a la puesta en música de textos de Federico García Lorca, indica que Baroncelli habrá confeccionado esta voz léxica a raíz de la participación de Baron-Supervielle en el concierto de música electroacústica que tuvo lugar en el Museo de Arte de San Pablo, y que generó repercusión en la prensa local ${ }^{41}$. En un artículo publicado en O Estado de São Pablo, el 1 de abril de 1982 se destaca justamente idéntico repertorio, con la misma referencia errónea al Romancero gitano.

36 Entre ellos se destacan en orden cronológico: Primer Congreso de Educación Artística de San Pablo. Conferencia: "El aporte de los sonidos concretos en la música actual" (1974); Conferencia explicativa sobre música concreta, y Concierto de música electroacústica, Museo de Arte de San Pablo (MASP) (1982), evento patrocinado por la Alianza Francesa de San Pablo; Primer encuentro paulista de música electroacústica, organizado por la Sociedade Brasileira de Musica Contemporánea (1983).

37 Agradezco esta información a Eliana Monteiro da Silva.

38 El 8 de agosto de 2016 la autora en su blog transcribió su primer artículo acerca del tema "MULHERES COMPOSITORAS" y aclara: "meu primeiro artigo sobre o tema", publicado en el periódico Brasil Mulher, São Paulo, ano I, nr. 5, 1976, p.15. Disponible en http:/ / mulheres-compositoras. blogspot.com/ [acceso: 25 de noviembre de 2020].

39 A este respecto es apropiado señalar que el primer libro acerca del tema publicado en Argentina es de 1950. Se trata de Mujeres compositoras, de la musicóloga Zulema Rosés Lacoigne, en edición de la autora, y resulta una rica fuente de época, ya que está escrito con valiosa rigurosidad.

40 Estos poemas no integran el Romancero gitano sino la sección “Andaluzas”, del libro Canciones de Federico García Lorca (Dezillio 2019: 5).

41 "A música electroacústica de Susana Baron", O Estado de São Pablo, (01-04-1982). Documento hemerográfico perteneciente al FPSBS-AMA-INMCV. 
Episodio III: París, 1954

El 25 de enero de 1954 el productor de las Emisiones de Música de Cámara de la RTF escribió una carta desde París a Madame Suzanne Baron-Supervielle, a su casa en São Paulo (ver Figura 5$)^{42}$.

Querida señora,

He recibido su carta que acompaña su Divertissement pour neuf instruments. Me gustaría verla cuando llegue a Francia a finales de abril para establecer juntos en qué fecha, a finales de junio, se podría realizar la ejecución de su Divertimento o proceder a su registro. No deje de llamarme tan pronto como llegue a París [...] (P. Capdevielle 25 de enero, 1954) ${ }^{43}$.

Finalmente, la obra se registró el 10 de junio de 1954 y su emisión tuvo lugar dos días después. La interpretación estuvo a cargo de los solistas de la Orquesta Nacional ${ }^{44}$ con la dirección de Marius Constant (Mansilla 1999: 245).

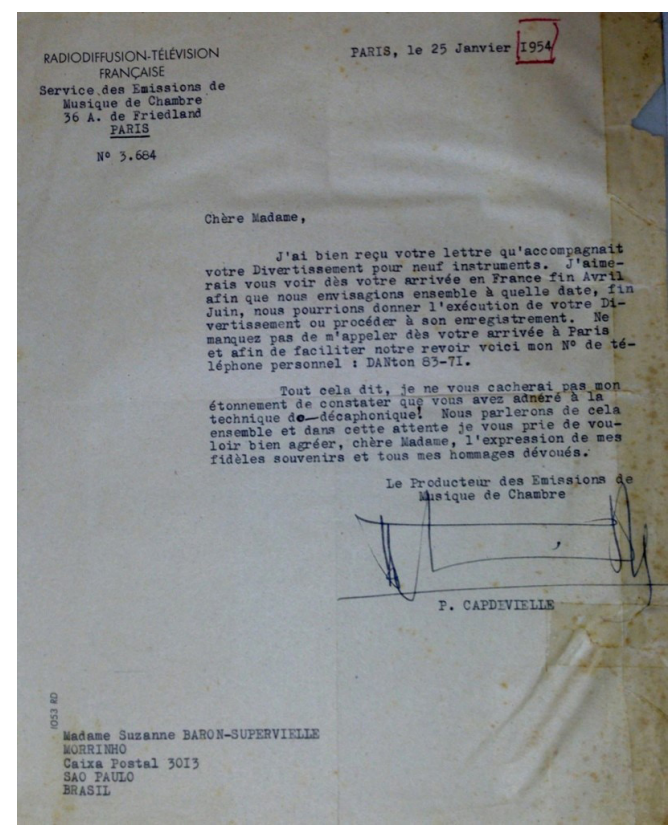

Figura 5: Carta de P. Capdevielle a Susana Baron-Supervielle

42 El destinatario figura de la siguiente manera: Madame Suzanne Baron-Supervielle/ Morrinho/ Caixa Postal 3013/ Sao Pablo/ Brasil. Documento perteneciente al FPSBS-AMA-INMCV.

${ }^{43}$ En el original en francés: Chère Madame/J'ai bien reçu votre lettre qu'accompagnait votre Divertissement pour neuf instruments. J'aime-rais vous voir dès votre arrive en France fin Avril afin que nous envisagions ensemble à quelle date, fin Juin, nous pourrions donner l'exécution de votre Divertissement ou procéder à son enregistrement. Ne manqué pas de m'appeler dès votre arrive à Paris. [Documento perteneciente al FPSBS-AMA-INMCV].

44 Flauta: Fernand Dufrène; Clarinete: Maurice Cliquennois; Saxo Tenor: Lucien Daqué; Fagot: René Plessier; Trompeta: Ludovic Vaillant; Violín: Henri Brongebaque; Violín:Jean Emmanuel; Viola: André Focheu; Violonchelo: Jacques Nels; Direccion: Marius Constant. 
Este no era el primer registro de Baron-Supervielle que la Difusora Francesa ofrecía. En 1950 había difundido su Cuarteto para cuerdas [Quartour] a cargo del Cuarteto Pascal ${ }^{45}$, obra también estrenada en Buenos Aires, dos años antes, por el Cuarteto Haydn ${ }^{46}$. En ocasión de aquella emisión, la invitación de la radioemisora francesa presentaba a BaronSupervielle como sigue:

Suzanne BARON-SUPERVIELLE es la sobrina de Jules Supervielle, eminente poeta, autor de Bolívar, a partir del que Darius Milhaud creó recientemente una ópera. / De nacionalidad argentina, Susana Baron-Supervielle es una joven exquisita, muy apegada a la cultura francesa. / Ella reside en São Paulo, Brasil, pero hizo frecuentes visitas a Francia, donde sigue estando en contacto con los círculos literarios y artísticos. / Apasionada de la música, fue alumna de Nadia Boulanger, y entre otras, tiene piezas para piano y numerosas melodías sobre poemas populares españoles. / A pesar de estar muy influenciada por los grandes maestros franceses, tiene un lenguaje personal cuyo modernismo está siempre temperado por un clasicismo muy puro. / Podríamos decir que SBS es una verdadera música francesa (Weil, 4 de julio, 1950) ${ }^{47}$.

En apariencia, la radiodifusora tenía buen conocimiento de la obra que BaronSupervielle había desarrollado hasta el momento, sus ciclos de poemas franceses y sus dos ciclos con Canciones de F.G. Lorca; quizá estos antecedentes son la causa de la sorpresa de P. Capdevielle, productor de Emisiones de Música de Cámara de la radiodifusora, cuando descubrió el lenguaje propuesto por su Divertissement:

¡No voy a ocultar mi sorpresa al constatar que usted ha adherido a la técnica dodecafónica! Ya hablaremos de esto juntos y, mientras tanto, le ruego que acepte por favor, querida señora, el testimonio de mis sinceros recuerdos y mi dedicado respeto (P. Capdevielle, 25 de enero, 1954) 48.

45 Gacetilla de la RTF. [Documento perteneciente al FPSBS-AMA-INMCV].

${ }^{46}$ La audición tuvo lugar en el Instituto Francés de Estudios Superiores, tercera audición de abono. El Cuarteto estaba integrado por: Eduardo Acedo, Carlos Sampedro, Liberto Guidi y Washington Castro. "Tres Cuartetos se ejecutaron ayer", 1948, s/d. [Documento hemerográfico perteneciente al FPSBS-AMA-INMCV].

47 Texto de Maxime Weil en ocasión de la emisión de "Quatour" de SBS por la Radiodiffusion Francaise (Finlande, 4 de juin 1950). Texto original en francés: Suzanne Baron-Supervielle est la nièce de Jules Supervielle, l'emitent poète, auteur de Bolivar, dont Darius Milhaud a tiré un drâme lyrique crée tout récemment à l'Opéra./ De nationalité argentine, Suzanne Baron-Supervielle est une exquise jeune femme, très éprise de cultura française. / Elle reside au Bresil, à Sao Paulo, mais fait de fréquents séjours en France aù elle ne cesse d'être en contact avec les milieux littéraires et artistiques. / Passionnée de musique, elle a été l'élève de Nadia Boulanger, et on lui doit déjà, entre autres ouvrages, des pièces pour piano et de nombreuses mélodies sur des poèmes populaires espagnols. / Encore qu'elle soit très nettement influencée par les grands maîtres française, elle a un langage personnel dont le modernisme es toujours tempéré par un classicisme très pur. [Documento perteneciente al FPSBS-AMA-INMCV].

48 Texto original en francés: Tout cela dit, je ne vous cacherai pas mon étonnement de constater que vous avez adhere a la technique dodécaphonique! Nous parlerons de cela ensemble et dans cette attente je vous prie de vouloir bien agréer, chère Madame, l'expression de mes fidèles souvenirs et tous mes hommages dévoués./ Le Producteur des Emissions de Musique de Chambre./ P. Capdevielle. [Documento perteneciente al FPSBS-AMA-INMCV]. 


\section{Episodio IV: Buenos Aires, Agrupación Nueva Música}

El ingreso de Susana Baron-Supervielle como miembro de la Agrupación Nueva Música (en adelante ANM) se registró en las gacetillas redactadas con ocasión del trigésimo y cuadragésimo aniversario de la agrupación ${ }^{49}$. Ambos relatos datan la incorporación de la compositora durante la década de 1950, años que se describen en estos documentos como de ampliación y reorganización, factores que según estos escritos motivaron el cambio en la denominación del grupo:

A partir de la década del 50, y desde entonces bajo la presidencia de Odile Baron-Supervielle, "Conciertos Nueva Música" se denominó "Agrupación Nueva Música", dado el aumento del número de sus integrantes y la nueva reorganización. Ingresan nuevos compositores: César Franchisena, Mauricio Kagel, Francisco Kröpfl, Nelly Moretto, Carlos Rauch y Susana Baron Supervielle ${ }^{50}$.

Según estas fuentes entonces, en los años en que Susana comenzó a participar de la ANM, su hermana Odile pasó a ocupar su presidencia ${ }^{51}$. A pesar de que esta información está contenida en un documento creado por la misma agrupación, su contenido difiere de aquel provisto por estudios especializados en el tema, al menos en dos datos: el año en que Conciertos de la Nueva Música se constituyó como Agrupación Nueva Música fue 1944 -y no 1950- (Corrado 2010: 258; Fugellie/Richter-Ibáñez 2019: 170). Al mismo tiempo Daniela Fugellie y Christina Richter-Ibáñez documentan que en 1952 (2019: 182) Odile integraba la comisión directiva como vicepresidenta y la presidenta era Sara Robirosa. Respecto de estas inexactitudes difundidas en las gacetillas de la agrupación, es posible comprobar en programas de mano contenidos en el archivo personal de Susana que la primera incorporación de una obra suya en los conciertos es en la audición número 100 de 1957, año en que también Odile era presidenta y la misma Susana vocal (junto con buena parte de sus colegas miembros) (ver Figuras 6 y 7 ).

49 “Treinta años de la Agrupación Nueva Música (1937-1967)” y "Trayectoria de la Agrupación Nueva Música 1937-1977”. Ninguno de los dos escritos declara autoría.

50 “Treinta años de la Agrupación Nueva Música (1937-1967)”. En la versión de 1977 -“Trayectoria de la Agrupación Nueva Música 1937-1977”- la información se refiere de modo casi idéntico, pero se agrega el rol de Paz: "A partir de la década del 50, bajo la presidencia de Odile Baron-Supervielle y la dirección artística de Juan Carlos Paz, 'Conciertos Nueva Música' pasa a denominarse 'Agrupación Nueva Música’, dado el incremento del número de sus integrantes. Ingresan los nuevos compositores César Franchisena, Mauricio Kagel, Francisco Kröpfl, Nelly Moretto, Carlos Rauch y Susana Baron Supervielle".

51 Recordemos que Odile Baron-Supervielle (1915-2016) desempeñó en su larga vida una prolífica carrera como escritora y periodista, que comenzó en el diario francés local Le Quotidien. Los mencionados vínculos familiares con la intelectualidad porteña y su amistad con Eduardo Mallea la acercaron al ambiente cultural promovido por Victoria Ocampo y el grupo de la revista Sur. Largos años colaboró con el suplemento literario del diario La Nación con entrevistas a destacadas personalidades del ámbito de la cultura internacional y con la columna Hechos y Figuras del mismo diario. También escribió para el diario La Prensa, realizó audiciones radiales y formó parte del directorio de la Alianza Francesa durante muchos años. "Odile Baron Supervielle: periodista cultural de varias orillas", La Nación (30-102016). Disponible en : https://www.lanacion.com.ar/cultura/odilebaron-supervielle-periodista-culturalde-varias-orillas-nid1951709 [acceso: 20 de diciembre de 2019]. El archivo sonoro de sus audiciones radiales y los recortes de su producción periodística se encuentran en el Centro de Documentación de Villa Ocampo, ubicado en Beccar, provincia de Buenos Aires. http:/ / unescovillaocampo.org/web/ centro-de-documentacion/ [acceso: 26 de noviembre de 2019]. 


\section{P ROG R M A}

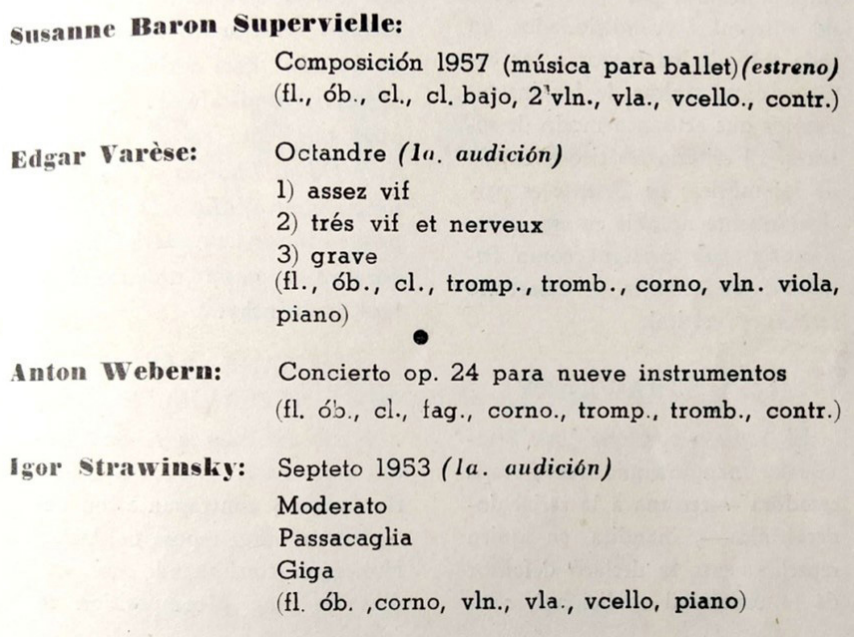

Figura 6: Programa de mano de la $100^{\circ}$ Audición de la ANM: detalle de las obras interpretadas

\section{agrupación nueva música}

\section{Comisión Directiva:}

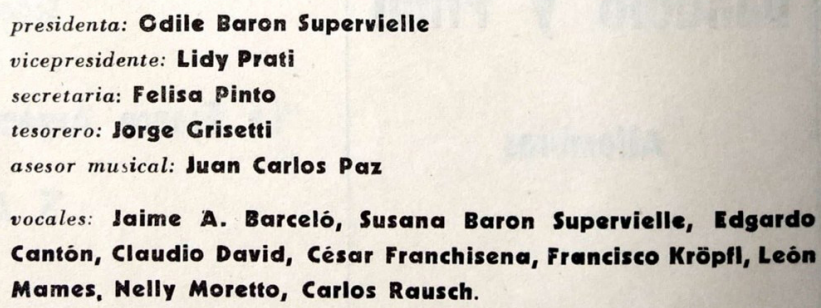

Figura 7: Programa de mano de la $100^{\circ}$ Audición de la ANM: miembros de la Comisión Directiva

Es importante destacar que este concierto se trató de una audición extraordinaria con motivo del vigésimo aniversario de Nueva Música, y para la ocasión se confeccionó un programa integrado por: Concierto op. 24 para nueve instrumentos de Anton Webern; Septeto de Igor Stravinsky; Invención 1957 de Suzanne Baron-Supervielle y Octandre de Edgard Varese (ver Figura 8). En la descripción que hacen de este programa Fugellie y Richter-Ibáñez mencionan que "figura una obra dodecafónica compuesta por un nuevo miembro de la agrupación" (2019: 194). Las investigaciones de las autoras permitirían situar, entonces, el ingreso de Susana Baron-Supervielle a la ANM en un momento cercano a la fecha de este concierto, aunque se lamenta que no se destaque su nombre junto con el resto de los 
compositores de este programa, a pesar de ser la única representante de la comunidad local 52 .

En la presentación que hace de la compositora, el programa de mano informa que "en [San Pablo] y luego en Bs. As. estudió la técnica dodecafónica con Hans Koellreuter [sic] y con Juan Carlos Paz respectivamente". El texto no olvida destacar que:

Divertissement sériel sérieuse [sic] para nueve instrumentos obtuvo el primer premio en un certamen internacional realizado en Tokyo $[s i c]$ en 1953 siendo ejecutado al año siguiente en París en la Radiodifusión Francesa bajo la dirección de Maurice [sic] Constant (Programa de mano ANM, audición 100a, 22 de julio, 1957) ${ }^{53}$.

La obra que la gacetilla promueve como Invención 57 (ver Figura 8), en realidad es Composición 57 (ver Figura 6) y se trata de música para ballet como informa el programa. La misma fuente detalla:

Escrita en la técnica dodecafónica condicionada a un criterio heterodoxo y evolucionista aplicado a problemas del espacio sonoro, ritmos, alturas e intensidades de sonido, esta composición señala una visible evolución dentro de las tendencias de avanzada que se practica en nuestro medio (Programa de mano ANM, audición 100a, 22 de julio, 1957).

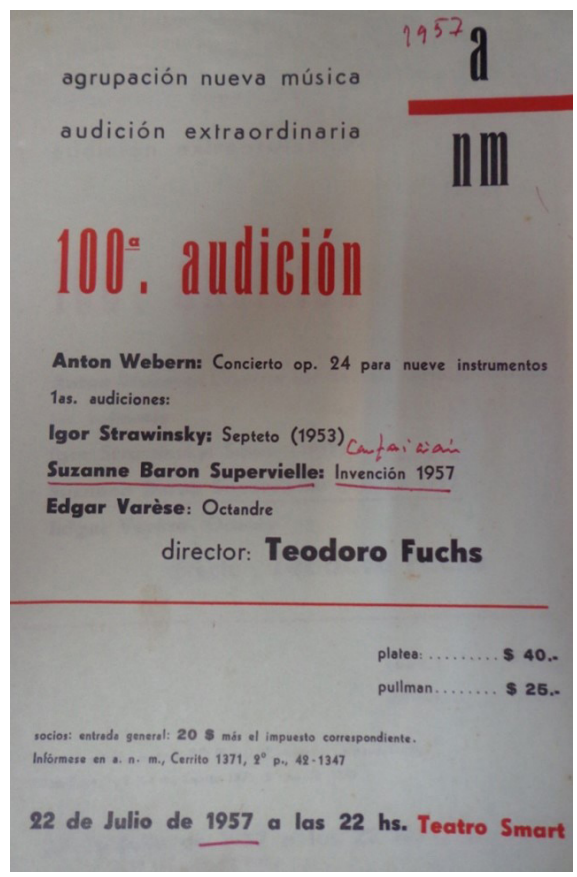

Figura 8: Gacetilla de la $100^{\circ}$ Audición de la ANM.

Estreno de Invención 1957 de Susana Baron-Supervielle

52 Los datos de autoría y nombre de la obra están detallados en el apéndice número 1, del mismo trabajo, que organiza los programas de conciertos entre 1937 y 1957 . Sin embargo, la falta de referencia a su nombre de pila genera confusión debido a que su hermana también formaba parte de la Agrupación (Fugellie/Richter-Ibáñez: 2019: 227).

53 Documento perteneciente al FPSBS-AMA-INMCV. 
$\mathrm{Al}$ año siguiente se estrenó Sonnet, en versión para canto y piano sobre texto de Jules Supervielle ${ }^{54}$, el primer poema musicalizado a partir del sistema de doce sonidos ${ }^{55}$. El programa de mano de este estreno fue enviado por su hermana Odile a São Paulo con la firma de sus colegas miembros de ANM, y en él se destaca el aprecio de Juan Carlos Paz ("Gracias, Suzanne, por el suave y dulce lirismo con que nos hizo felices a todos") y Francisco Kröpfl ("Su soneto Susana hace evidente que usted es música") 56 (ver Figura 9).

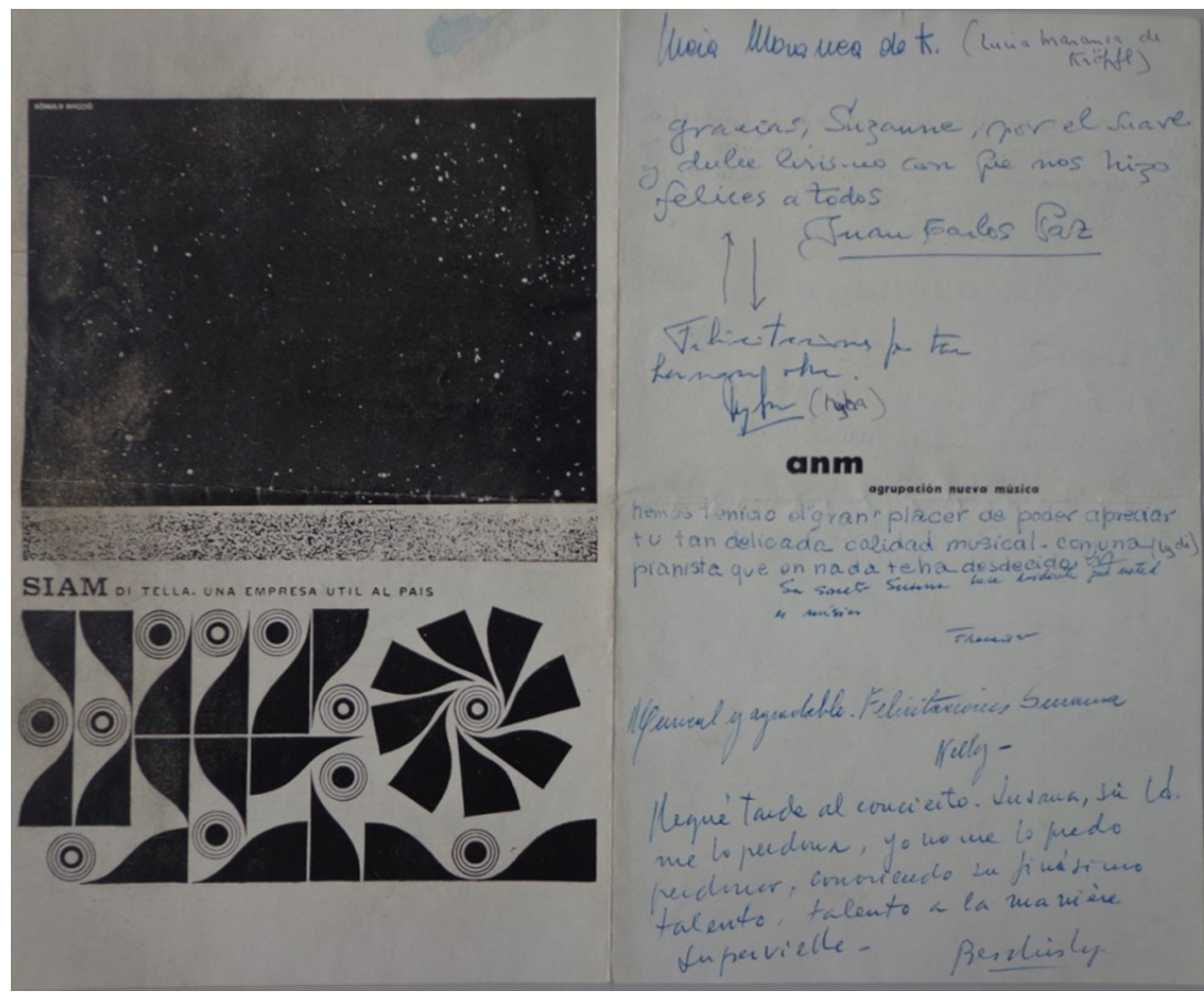

Figura 9: Programa de mano, audición 108 (3-08-1959): estreno de Sonnet

Una vez más se observa la referencia a Baron-Supervielle con el nombre de pila en versión francesa "Suzanne" como autora de Invención 57 y como dedicataria de Juan Carlos Paz ante el estreno de Sonnet.

A pesar de que la misma compositora menciona en documentos personales la ejecución de Divertissement sériel en los conciertos organizados por la ANM, no he dado con documentos

54 Posterior a la primera versión para canto y piano hay una segunda para canto y seis instrumentos de 1962, otra para canto y piano de 1982, una para voz y guitarra de 1990 y la última para voz sola del mismo año.

55 La musicalización de textos poéticos resulta fundamental en la producción de Susana BaronSupervielle y supera las cien obras. Ver Dezillio 2017b.

56 Programa de mano presente en el FPSBS-AMA-INMCV. 
que la confirmen ${ }^{57}$. Sin embargo, la presencia asidua de obras de su repertorio en los conciertos se postula como la concreción de esa triple identidad con la que Baron-Supervielle definió su producción musical: un árbol genealógico con marcada impronta francesa, los consumos culturales y la sociabilidad de la elite porteña argentina y una prolongada residencia como inmigrante en Brasil (donde ensaya una versión latinoamericana para el dodecafonismo vienés). En este sentido, Divertissement sériel se pretende corolario de una temporalidad rasgada por la fragmentación espacial y el internacionalismo estético que traza la vida de esta obra (y de los sujetos que allí coadyuvan). Disputada por los distintos territorios que conforman su identidad, espacios de migración, Divertissement sériel-su título más difundido-o Divertimento-a secas, como la menciona Koellreutter en su postal-quiere ser Divertimento serial, quiere ser en Buenos Aires y completar los estadios de una consagración plena de la mano de la autoridad local e impulsor pionero del dodecafonismo como lo era Juan Carlos Paz.

\section{CONCLUSIONES}

La interpretación de Divertissement sériel promovida por la ANM resulta un eslabón perdido en este devenir. Por lo antes mencionado, es posible pensar que Composición 57, creada ese mismo año de 1957, significó para su autora una utilización más personal ("criterio heterodoxo") y con mayor vigencia ("visible evolución”) respecto de lo que había sido su primera incursión en la técnica dodecafónica. Por otra parte, y debido a que sus conocimientos en materia de dodecafonismo fueron resultado de estudios con Koellreutter primero y con Paz después, es posible considerar que Composición 57 haya sido el resultado de la guía de Paz, así como el Divertissement lo había sido de sus clases con Koellreutter, y que la suma de estos factores haya favorecido su difusión.

Seguidora de la modernidad musical de los años treinta en Buenos Aires y con pocos antecedentes de instrucción escolástica con la que se formaron otras compositoras argentinas, Susana Baron-Supervielle se esforzó por acompañar la experiencia de la vanguardia desde donde se encontrara. Aunque realizó sus primeros estudios de composición con Gilardo Gilardi nunca asistió al Conservatorio Nacional, el espacio de formación por excelencia de todas sus contemporáneas, y con este gesto se constituyó como un caso singular dentro del grupo de las primeras compositoras profesionales en Argentina (Dezillio 2017c) ${ }^{58}$.

Cuando decidió aprender la técnica de composición dodecafónica y realizó los cursos en la Escola Livre de Musica Pró-Arte de São Paulo con Koellreutter, Baron-Supervielle tenía más de cuarenta años, veinte años más que la media de sus compañeros y cinco más que su maestro. En medio de la juventud, se mostraba amable, pero de poca conversación, según la recuerda Vinholes, y permanecía en la escuela únicamente el tiempo estricto de sus clases ${ }^{59}$.

Nacida en el Centenario de la Revolución de Mayo con el auge de las estéticas nacionales, Baron-Supervielle nunca se acercó al nacionalismo musical. En su lugar se mantuvo

57 La consulta al archivo de esta agrupación, presente en la Biblioteca Nacional de la República Argentina, no arrojó resultados que permitan documentarlo.

58 Otro caso de esta misma generación que se acercó al dodecafonismo en los años cincuenta es el de Montserrat Campmany, aunque con una experiencia biográfica completamente diferente. El número de casos, por supuesto, se amplía en generaciones siguientes.

$59 \mathrm{Su}$ edad no era el único factor que llamaba la atención en la escuela paulista, también contradecía la expectativa de sus compañeras mujeres por usar pantalones largos, un hábito considerado "poco femenino" en la época. Comunicación personal por correo electrónico con Luiz Vinholes (28 de enero, 2017). 
apegada a la idea de asumir progresivamente las tendencias que se manifestaron como nuevas en cada etapa: un primer neoclasicismo, más tarde ensayos dodecafónicos y aproximaciones al serialismo libre, y luego la música electroacústica. En su identidad cosmopolita se observa que la lengua materna es el francés. Francés es el idioma que registra esta obra y el que queda fijado en su título, pero quizá haya sido esa "fuerza creadora" -desarrollada a partir de la "propia personalidad", estimulada por las clases de Koellreutter-, la que le permitió hacer del lenguaje musical, su patria.

\section{BIBLIOGRAFÍA}

Baroncelli, Nilcéía Cleide da Silva

1987 Mulheres compositoras: elenco e repertório. São Paulo: Roswitha Kempf Editores.

2016 "MULHERES COMPOSITORAS (meu primeiro artigo sobre o tema)". Transcripción de un artículo publicado el periódico Brasil Mulher, São Paulo I/5, 1976, p. 15. Disponible en el blog de la autora: http:/ / mulheres-compositoras.blogspot.com/ [acceso: 20 de diciembre de 2019].

Baron-Supervielle, Susana

199929 poemas cantados. Composiciones de Susana Baron-Supervielle sobre poemas de San Juan de la Cruz, Alejandra Pizarnik y Jules Supervielle. Canto: Nélida Saporiti. [Folleto del CD]. Buenos Aires: Edición de la autora.

Corrado, OMAR

2010 Música y modernidad en Buenos Aires. Buenos Aires: Gourmet Musical Ediciones.

Dezillio, Romina

2017a "Inventario del Archivo de Susana Baron-Supervielle presente en el Instituto Nacional de Musicología 'Carlos Vega'”. Buenos Aires: inédito.

2017b "1928-1999: Un diario de voces para las canciones de Susana Baron-Supervielle”, Actas de las I Jornadas de Investigación del Instituto de Artes del Espectáculo. Buenos Aires: Instituto de Artes del Espectáculo, FFyL, UBA. Disponible en http://eventosacademicos.filo.uba.ar/index. php/JIIAE/IAE2017/paper/viewFile/1950/2312 [acceso: 20 de diciembre de 2019].

2017c "Las primeras compositoras profesionales de música académica en Argentina: logros, conquistas y desafíos de una profesión masculina”, Música y mujer en Iberoamérica: haciendo música desde la condición de género. Actas del III Coloquio de Ibermúsicas sobre Investigación Musical. Juan Pablo González (coordinador y editor). E-book. Disponible en: http://www.ibermusicas. org/es/musical_investigations/5 [acceso: 20 de diciembre de 2019].

2019 "Susana Baron Supervielle y sus Canciones de Federico García Lorca. Un abrazo intermitente”, Actas de las III Jornadas de investigación del Instituto de Artes del Espectáculo. Buenos Aires: Instituto de Artes del Espectáculo, FFyL, UBA. Disponible en http://eventosacademicos. filo.uba.ar/index.php/JIIAE/JIAEIII/paper/viewFile/4714/2805 [acceso: 20 de diciembre de 2019].

Fugellie, Daniela Alejandra

2013 "Las relaciones de Luigi Nono con los compositores latinoamericanos de vanguardia", Boletín Música, Revista de Música Latinoamericana y Caribeña, 35, pp. 3-29.

Fugellie, Daniela y Christina Richter-Ibañez

2019 "Veinte años de Nueva Música (1937-1957)", Recorridos. Diez estudios sobre música culta argentina de los siglos XX y XXI. Omar Corrado (editor). Buenos Aires: Editorial de la Facultad de Filosofía y Letras, Universidad de Buenos Aires, pp. 159-234.

Malvestio, Anna

2013 "Los espacios de la migración en el universo femenino", Las migraciones ítalo-rioplatenses. Memoria cultural, literatura y territorialidades. Adriana Cristina Crolla (directora). Santa Fe: Ediciones UNL, pp. 227-244. [E-Book]. 
Mansilla, Silvina

1999 "Baron Supervielle, Susana”, Diccionario de la música española e hispanoamericana. Emilio Casares Rodicio (director). Madrid: SGAE, vol. 2, pp. 244-245.

Monjeau, Federico

2004 "Progreso", La invención musical. Ideas de historia, forma y representación. Capítulo 1. Buenos Aires: Paidós, pp. 15-68.

Monteiro da Silva, Eliana

2017 "Compositoras brasileiras no contexto da música erudita: uma história de luta contra a invisibilidade”, Música y mujer en Iberoamérica: haciendo música desde la condición de género. Actas del III Coloquio de Ibermúsicas sobre investigación musical. Juan Pablo González (coordinador y editor). E-book. Disponible en: http://www.ibermusicas.org/es/musical_investigations/5 [acceso: 20 de diciembre de 2019].

Monteiro da Silva, Eliana, Amilcar Zani, Marisa Candido

2019 "A Composição de Eunice Katunda no contexto político e musical brasileiro", Revista Extraprensa, 12/2, pp. 114-137. doi: https://doi.org/10.11606/extraprensa2019.157504.

Nichols, Robert S.

1980 "Senart", The New Grove Dictionary of Music and Musicians. Stanley Sadie (editor). Londres: Macmillan, tomo 17, p. 126.

Nogueira, Lenita W. M. y Lilia de Oliveira Rosa

2012 "Os Seminários de Música da Pró-Arte de São Paulo", Anais do II Simpósio Internacional de Musicologia da UFRJ Teoria, Crítica e Música na Atualidade. Maria Alice Volpe (editora). Rio de Janeiro: Universidade Federal do Rio de Janeiro, pp. 125-156.

PARAskevaídis, Graciela

1985 "Música dodecafónica y serialismo en América Latina," La del taller, 3. Disponible en: http:// www.latinoamerica-musica.net. [acceso: 20 de diciembre de 2019]

Pinheiro de Avila, Danilo

2016 "Hans Joachim Koellreutter: uma experiência de vanguarda nos trópicos? (1938-1951)". Dissertação (Mestrado em História). São Paulo: Universidade Estadual Paulista. Faculdade de Ciências Humanas e Sociais.

Rosés Lacoigne, Zulema

$1950 \quad$ Mujeres compositoras. Buenos Aires: la autora.

Scarabino, Guillermo

2000 El Grupo Renovación (1929-1944) y la 'nueva música' en la Argentina del siglo XX. Buenos Aires: Instituto de Investigación Musicológica "Carlos Vega”, Universidad Católica Argentina.\}

Spratt, Geoffrey K.

1980 "Honegger, Arthur", The New Grove Dictionary of Music and Musicians. Stanley Sadie (editor). Tomo VIII. Londres: Macmillan, p. 679.

VAlenti Ferro, Enzo

1992100 Años de Música en Buenos Aires. De 1890 a nuestros días. Buenos Aires: Ediciones de Arte Gaglianone.

Vinholes, Luiz Carlos

2006 "Depoimento. Retalhos de uma amizade apresentados no evento 'Relembrando Koellreutter', realizado no Centro Aura-Soma Paz (CAP), em Tiradentes (MG). Inédito.

2011a "Primeira visita à Península das Coréias", Usina de letras (6 de septiembre). Disponible en: http:/ / www.usinadeletras.com.br/exibelotexto.php?cod=61964\&cat=Artigos [acceso: $17 \mathrm{de}$ enero de 2018].

$2011 b$ "Os docentes da escola livre de música da pró-arte nos anos 1950", Usina de letras (14 de octubre). Disponible en: http://www.usinadeletras.com.br/exibelotexto. php?cod=62261\&cat=Artigos [acceso: 17 de enero de 2018]. 
2011c "A Pró-Arte, A Escola de Música e os Cursos Internacionais de Férias de Teresópolis", Usina de letras (8 de noviembre). Disponible en: http:/ /www.usinadeletras.com.br/exibelotexto. php?cod=62506\&cat=Artigos [acceso: 17 de enero de 2018].

2013a "Música eletrônica No Brasil Nos Anos 1950". Música Em Contexto, 5/1, pp. 27-59. https:// periodicos.unb.br/index.php/Musica/article/view/11072. [acceso: 20 de diciembre de 2019].

2013b "Escola Livre de Música 'São Paulo”, Usina de letras (15 de mayo). http:/ /www.usinadeletras. com.br/exibelotexto.php?cod=67632\&cat=Artigos [acceso: 17 de enero de 2018].

\section{Fuentes manuscritas}

- $\quad$ Baron-Supervielle, Susana, carta enviada desde San Pablo a Buenos Aires, remitida a Silvina Luz Mansilla (02-04-1990).

- $\quad$ Baron-Supervielle, Susana, curriculum vitae.

- $\quad$ Bathori, Jane, carta desde Buenos Aires dirigida a Charles Koechlin (1934).

- $\quad$ Capdevielle, P., carta desde París a Susana Baron-Supervielle (25 de enero, 1954).

- $\quad$ Koellreutter, Hans-Joachim, postal remitida a Suzana Tresca desde Tokio, a la dirección de la Escuela (28 de noviembre, 1953).

- Weil, Maxime, texto redactado en ocasión de la emisión de "Quatour" de Susana BaronSupervielle por la Radiodiffusion Francaise (Finlande, 4 de junio, 1950).

\section{Otras fuentes}

- Agrupación Nueva Música, "Treinta años de la Agrupación Nueva Música (1937-1967)". Gacetilla adjunta al programa de mano de la Audición 146, Temporada 1967 de ANM (9 de agosto, 1967). Buenos Aires: Sala Audiovisual del Museo Nacional de Bellas Artes.

- Agrupación Nueva Música, “Trayectoria de la Agrupación Nueva Música 1937-1977”. Gacetilla de difusión.

- $\quad$ Agrupación Nueva Música, programas de mano.

- $\quad$ Pinto, Felisa, "Retrato de dama con piano", Página 12 (15 de octubre, 1999), pp. 6-7.

- S S S S "Tres Cuartetos se ejecutaron ayer", La Prensa (1948), s/d.

- $\quad$ S/D, "Muera el solfeo", Primera Plana (26 de julio, 1966), p. 85.

- $\quad$ S/D, "A música electroacústica de Susana Baron”, o Estado de São Pablo, (01 de abril, 1982).

- S/D, "Odile Baron-Supervielle: periodista cultural de varias orillas", La Nación, (30 de octubre, 2016).

\section{Fuentes sonoras}

- $\quad$ Baron-Supervielle, Susana. 1954. Divertissement sériel. Registro fonográfico con el título de Divertissement pour neuf instrument, disponible en la sección Ina Teque, depósito legal de la Radiodiffusion-Télévision Française [RTF], con sede en la Biblioteca Nacional de Francia.

- $\quad$ Kerr, Samuel. "Escola Livre de Música", en Ideias musicais (programa de radio online). Disponible en: http://culturafm.cmais.com.br/escola-livre-de-musica. [acceso: 28 de noviembre de 2019]

\section{Abreviaturas}

ANM: Agrupación Nueva Música.

FPSBS-AMA-INMCV: Fondo personal Susana Baron-Supevielle, Archivo de Música Académica del Instituto Nacional de Musicología "Carlos Vega".

RTF: Radiodiffusion-Télévision Française [Difusora de Radio y Televisión Francesa].

SADAIC: Sociedad Argentina de Autores y Compositores de Música. 